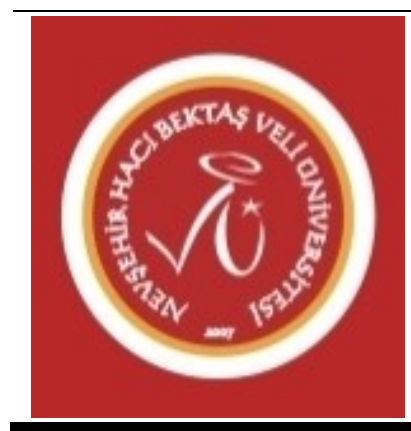

Nevşehir Bilim ve Teknoloji Dergisi

Araştırma Makelesi (Research Article)

Makale Doi: 10.17100/nevbiltek.727589

Geliş Tarihi: 27-04-2020

Kabul Tarihi 30-06-2020

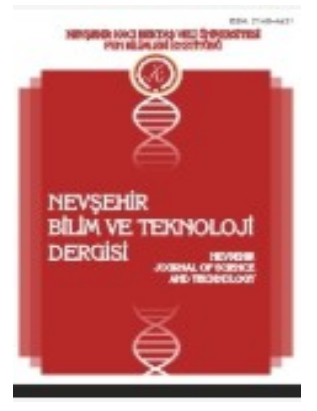

\title{
Başlık Malzemesi Türünün ve Başılı Sayısının Beton Basınç Dayanımı ve Elastisite Modülüne Etkisi ${ }^{1}$
}

\author{
Hasan BAYLAVLI 1, , Eren GÖDEK ${ }^{2}$ \\ ${ }^{1}$ Hitit Üniversitesi, Teknik Bilimler Meslek Yüksekokulu, İnşaat Teknolojisi Bölümü, Çorum \\ ORCID ID: 0000-0003-2627-4926 \\ ${ }^{2}$ Hitit Üniversitesi, Teknik Bilimler Meslek Yüksekokulu, Inşsaat Teknolojisi Bölümü, Çorum \\ ORCID ID: 0000-0002-3427-2317
}

Öz

Beton, günümüzde kullanılan en yaygın yapı malzemelerinden biri olarak kabul edilmektedir. Betonun basınç dayanımı ve elastisite modülü (E-modülü) değerleri, yapıda kullanılacak betonun kalitesi hakkında fikir veren ve betonarme sistemlerinin taşıma gücü hesaplarında kullanılan en önemli parametrelerdendir. Söz konusu parametreler, şantiye sahasında alınan numuneler kullanılarak laboratuvar ortamında belirlenmekte ve tasarıma uygunluğu denetlenmektedir. Ülkemizde kamu ya da özel kurum laboratuvarlarında genellikle inşaat teknikerleri bu tür deneylerin gerçekleştirilmesinde işgücü olarak görev almaktadır. Bu çalışma kapsamında, işgücü kaynaklı olarak karşılaşılabilecek farklı yükleme senaryoları (başlıksız, tek başlıklı ve çift başlıklı yükleme) belirlenmiştir. Bu senaryolara bağıı kalınarak, kükürt ve neopren malzemeler ile farklı kombinasyonlarda yükleme koşullarında oluşturulmuş ve bu koşullarda numunelerden elde edilen basınç dayanımı ve E-modülü değerleri kıyaslanmıştır. Sonuç olarak, başlık yapılmadan basınç ve E-modülü deneylerinden verimli sonuç elde edilemeyeceği, hem basınç hem de E-modülü deneylerinin gerçekleştirilmesi sırasında çift taraflı kükürt başlıklamanın gerekliliği bir kez daha ortaya konulmuştur. Kükürt başlıklamaya alternatif olarak sunulan neopren başlıklamanın, numune başlık birleşim bölgesinde oluşan gerilme yığılmaları nedeniyle başlısız durum, tek ve çift kükürt başlıklamaya kıyasla sırasıyla $\% 15, \% 8$ ve $\% 17$ oranında daha yüksek basınç dayanımı değerleri verdiği belirlenmiştir. Ancak, söz konusu gerilme yığılmalarının başlık bölgelerinde çatlamalara neden olarak E-modülü değerlerini tek başlıklı durumda \%5.1, çift başlıklı durumda ise \%3.7 oranında düşürdüğü görülmüştür.

Anahtar Kelimeler: Basınç, elastisite modülü, başlıklama, kükürt, neopren.

\section{The Effect of Capping Material Type and Number of Caps on Compressive Strength and Elastic Modulus of Concrete}

\begin{abstract}
Concrete is considered to be one of the most common building materials used today. The compressive strength and elastic modulus (E-modulus) values of concrete are among the most important parameters that give an idea about the quality of the concrete to be used in the structure and are used in the calculation of the bearing capacity of the reinforced concrete systems. These parameters are determined in the laboratory by use of samples taken at the construction site and their compliance with the design is checked. In our country, construction technicians generally work as labor force in conducting such experiments in public or private laboratories. In this study, different loading scenarios (uncapped, single capped and double capped loading conditions) that may be encountered by labor force are determined. Based on these scenarios, different loading conditions were formed in varying combinations by use of sulfur and neoprene materials and the compressive strength and E-modulus values obtained from the samples were compared under these conditions. As a result, the efficient results cannot be obtained from the compression and E-modulus tests without capping, and the necessity of double sulfur capping during the execution of both compression and E-modulus tests has been demonstrated once again. It has been found that the
\end{abstract}

\footnotetext{
${ }^{1} \mathrm{Bu}$ makale, 4. International Conference on Material Science and Technology in Kiz1lcahamam/ANKARA (IMSTEC 2019) sempozyumunda sözlü sunum yapılmıştır.

Sorumlu yazar e-mail: erengodek@hitit.edu.tr
} 
neoprene capping, which is offered as an alternative to sulfur capping, results $15 \%, 8 \%$ and $17 \%$ higher compressive strength values due to the stress accumulations occurring in the cap junction area when compared to uncapped, single and double sulfur capping conditions, respectively, However, it has also been found that these stress accumulations cause crack initiation from the capped regions, which decreasing the E-modulus values by $5.1 \%$ in the single capping and $3.7 \%$ in the double capping conditions.

Keywords: Compression, elastic modulus, capping, sulfur, neoprene.

\section{Giriş}

Beton, günümüzde kullanılan en yaygın yapı malzemelerinden biri olarak kabul edilmektedir [1]. Betonun basınç dayanımı değeri, yapıda kullanılacak betonun kalitesi hakkında fikir veren ve betonarme taşıma gücü hesaplarında kullanılan en önemli parametrelerden bir tanesidir [2]. Bu nedenle betondan alınan 150x150x150 mm lik küp ya da Ø150x300 mm boyutlarındaki silindir numuneler kullanılarak beton basınç dayanımı tayin edilmektedir [3]. Betonarme binaların tasarımında kullanılan bir diğer önemli beton özelliği de elastisite modülü (E-modülü)'dur. Beton E-modülü değerinin bulunmasında; basınç yüklemesi altında E-modülü tayini, ultrasonik ses geçirimliliği tayini ya da çeşitli deneysel formüller yaygın olarak kullanılmaktadır [4].

Basınç dayanımı, karakteristik silindir formdaki numuneler kullanılarak belirlenirken uygulanan kuvvetin numune kesitine eşit ve homojen bir şekil dağıtılabilmesi için numune tabanının (alt yüzey) ve perdah yüzeyinin (üst yüzey) düzeltilmesi gerekmektedir. Bu işleme "başlıklama" adı verilmektedir. Benzer şekilde, beton statik E-modülü değerinin belirlenmesinde de taban ve perdah yüzeyi başlıklanmış karakteristik silindir formdaki numunelerden faydalanılmaktadır. Silindir numuneler ilgili standardın öngördüğü elastik gerilme limitine kadar yüklenmekte ve numune üzerine yerleştirilen bir çerçeve ile numunenin şekil değiştirme değerleri kaydedilmektedir. Çizilen gerilme-şekil değiştirme $(\sigma-\varepsilon)$ eğrisinin tanımlanan elastik sınırları içerisinde kalan bölgede standarda uygun olarak E-modülü değerleri hesaplanabilmektedir [5].

Başlıklama işlemi bağ yapan ya da bağ yapmayan şekilde iki kısımda incelenebilir. Silindir numunelerin başlıklanması işleminde genellikle standardın öngördüğü kükürt+grafit, kükürt+filler, çimento ya da çimento+alçı karışımları gibi bağ yapan başlık türleri ya da bağ yapmayan çeşitli elastomerik malzemeler kullanılmaktadır [3, 6]. 1980’li yıllarda günümüze, özellikle laboratuvar uygulamalarında en çok tercih edilen başlıklıma yönteminin kükürt+grafit tozu karışımı olduğu görülmektedir [7]. Söz konusu başlıklamanın temel tercih nedeni çok hızlı bir şekilde sertleşerek yeterli basınç mukavemetine ulaşabilmesidir. Ancak, hazırlık aşamasında kükürt ve grafit tozlarının bir potada yüksek sıcaklıkta $\left(150-200^{\circ} \mathrm{C}\right)$ eritilmesi, eritme sırasında ortama salınan uzun vadede insan sağlığına zararlı olabileceği düşünülen bileşenler ve rahatsız edici koku gibi dezavantajları da bulunmaktadır [8]. İlaveten, benzer başlıklama yöntemlerinde yapılan sürekli malzeme giderleri kurumlara ekonomik açıdan bir maliyet yaratmaktadır. Söz konusu duruma alternatif bir çözüm olarak, yeniden kullanılabilir elastomerik malzemelerin başlık olarak kullanılması üzerine çeşitli çalışmalar yapılmıştır [7]. Yapılan bir çalışmada, kükürt karışımı ile poliüretan ve neopren malzemeler kullanılarak hazırlanan silindir numunelerin basınç dayanımları karşılaştııılmıştır. Bağ yapmayan malzemelerin başlıklamada kullanılabileceği ancak beton basınç dayanımı da dikkate alınarak yapılacak ön çalışmalarla belirli aralıklarla ASTM C 617 [9]'ye uygun olarak hazırlanan kükürt başlıklı numunelerle uygunluğunun karşılaştırılması gerektiği rapor edilmiştir [7]. Bir diğer çalışmada, alçı, kauçuk, ekstürüzyonla üretilmiş polistren (EPS) ve neopren başlıkların basınç dayanımına etkisi incelenmiştir [10]. Sonuç olarak alçı kullanımının zaman açısından elverişsiz olduğu, kauçuk ve EPS kullanımının da elde edilen dayanımlardaki varyasyonu arttırdığı belirtilmiştir. Ayrıca, EPS kullanımında en düşük basınç dayanımları elde edilmiştir. Neopren kullanımı ile düşük varyasyon değerlerinin elde edildiği ancak basınç dayanımlarının bir miktar arttığı rapor edilmiştir [10]. Richardson [11] tarafindan yapılan bir diğer çalışmada, basınç dayanımı $35 \mathrm{MPa}$ 'ın altındaki betonlarda kükürt ya da neopren başlıklamanın silindir numunelerin basınç dayanımına belirgin bir etkisi olmadığını belirtmiştir. 
Ülkemizde kamu ya da özel kurum laboratuvarlarında genellikle inşaat teknikerleri görev almaktadır. Yapılan bir araştırmada laboratuvar personelinde en çok ihtiyaç duyulan becerilerin öncelik sırasına göre beton, çimento ve agrega deneyleri olduğu belirtilmiştir [12]. Yapılan bir diğer çalışmada, hazır beton tesislerinde karşılaşılan sorunlardan biri olarak çalışacak kalifiye elaman sıkıntısının yaşandığı belirtilerek, yapı denetim firmalarının ve beton laboratuvarlarında yeteri kadar beton bilgisine sahip olmadığı rapor edilmiştir. Ayrıca, söz konusu firmalarda çalışan personelin Türkiye Hazır Beton Birliği (THBB) eğitim programlarından Mesleki Yeterlilik belgesi almasının zorunlu hale getirilmesi önerilmiştir [13].

Bahsi geçen durumlar göz önüne alındığında, beton basınç ve E-modülü deneylerinin gerçekleştirilmesi durumunda aşağıdaki senaryoların gerçekleşmesi olası görülmektedir;

- Silindir formdaki numunelerin herhangi bir başlıklama yapılmadan deneye tabi tutulması (başlıksız durum),

- Kalıp tabanının düz olduğu kabul edilerek yalnızca perdah yüzeyine başlık yapılması (tek başlıklı durum),

- Standarda uygun olarak her iki yüzeyinde başlıklanması (çift başlıklı durum),

$\mathrm{Bu}$ kısa kapsamlı çalışmada, laboratuvarlarda yaygın olarak kullanılan kükürt başlıklama ile neopren başlıklamanın yukarıda bahsi geçen durumlar ile kombine edilerek hem başlık türünün hem de başlıklama sayısının basınç ve E-modülü ölçümüne etkisi incelenecektir.

\section{Materyal ve Metot}

Deneysel çalışmalar kapsamında kullanılacak silindir formdaki beton numuneler Hitit Üniversitesi Beton Yol Şantiyesinden beton dökümü sırasında alınmıştır (Şekil 1). Beton yol imalatında kullanılacak tasarım C35/45 olarak hedeflenmektedir. Tasarımda kullanılan malzeme oranları Tablo 1'de sunulmuştur.
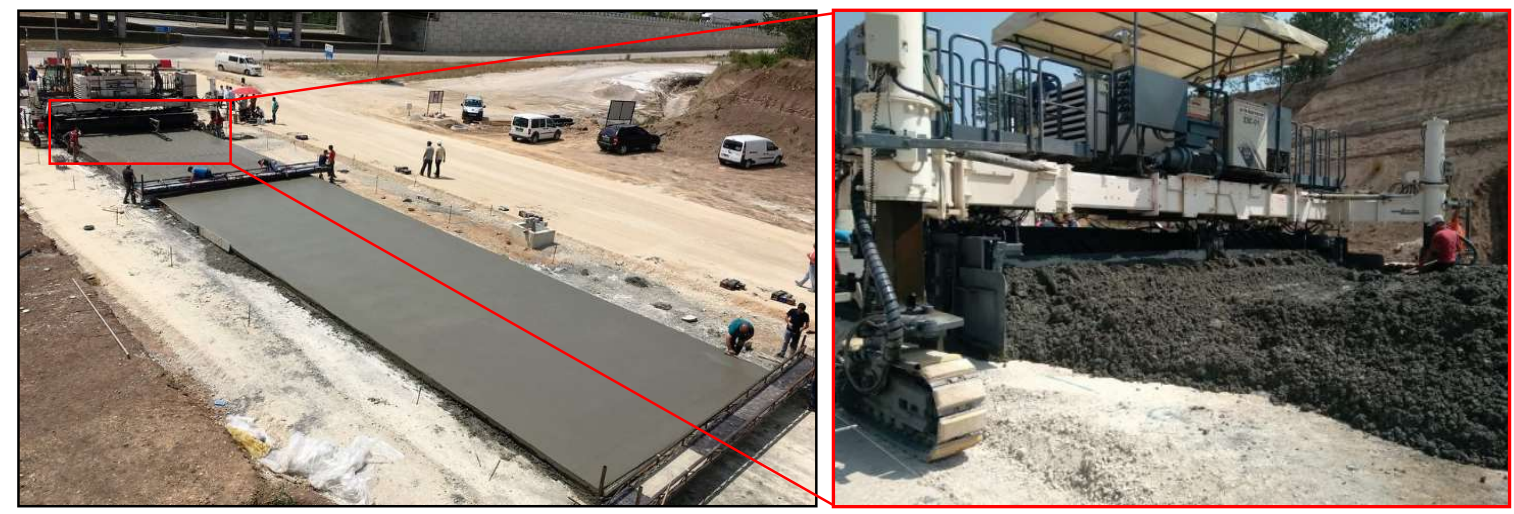

Şekil 1. Hitit Üniversitesi beton yol uygulaması

Tablo 1. Beton yol için malzeme oranları

\begin{tabular}{lcc}
\hline & Malzeme & Miktar $\left(\mathbf{k g} / \mathbf{m}^{\mathbf{3}}\right)$ \\
Çimento & & 370 \\
Su & & 170 \\
& $\mathbf{4 - 1 2} \mathbf{~ m m}$ & 385 \\
İri agrega & $\mathbf{1 2 - 2 2} \mathbf{~ m m}$ & 300 \\
& $\mathbf{1 9 - 3 8} \mathbf{~ m m}$ & 410 \\
İnce agrega & $\mathbf{0 - 4} \mathbf{~ m m}$ & 770 \\
\hline
\end{tabular}

Basınç deneyleri için 15 adet ve E-modülü deneyleri için 15 adet olmak üzere toplamda 30 adet silindir numune alımı gerçekleştirilmiştir. Numuneler 28 gün suda kür edilmiş ardından 180 gün laboratuvar ortamında bekletilmiştir. 
Deneysel çalışmalarda uygulanan program şeması Şekil 2'de gösterilmiştir. İlk olarak herhangi bir başlıklama işlemi yapılmadan (kontrol numuneleri ile) beton basınç dayanımları ve E-modülü değerlerinin belirlenmesi hedeflenmiştir. Ardından, kükürt karışımı ve neopren kullanılarak tek ve çift başlık olmak üzere farklı başlıklama kombinasyonlarında deney numuneleri hazırlanarak basınç ve E-modülü deneyleri gerçekleştirilmiştir (Şekil 2).

Her iki deneyde de 3000 kN yük kapasiteli ToniTechnik marka hidrolik basınç presi kullanılmıştır (Şekil 3). Kükürt karışımı başlık yapııııken standarda uygun bir potada kükürt+grafit tozu karışımı $160^{\circ} \mathrm{C}$ de karışıııırılarak ısıtılımış ve akıcı hale getirilmiştir. Ardından numuneler metal bir kalıba dökülen kükürt karışımının üzerine oturacak şekilde yerleştirilerek başlıklama işlemi tamamlanmıştır (Şekil 3a). Neopren başlıklama sisteminde ise metal bir plaka içerisine neopren malzeme yerleştirilmiş ardından numune üzerine konumlandırılmıştır (Şekil 3b).



Numunelerin elastisite modülü tayini deneyleri ASTM C469 [5] standardı doğrultusunda gerçekleştirilmiştir. Basınç gerilmesi değerleri basınç presi aracılı̆̆ıyla; birim şekil değiştirme değerleri de silindir numune üzerine yerleştirilen Zwick Roell marka bir deformasyon ölçme çerçevesi kullanılarak elde edilmiştir (Şekil 4). Kullanılan deformasyon ölçme çerçevesi numuneye 2 noktadan temas etmekte ve $\pm 2,5 \mathrm{~mm}$ aralığında yüksek hassasiyette veri almaktadır.

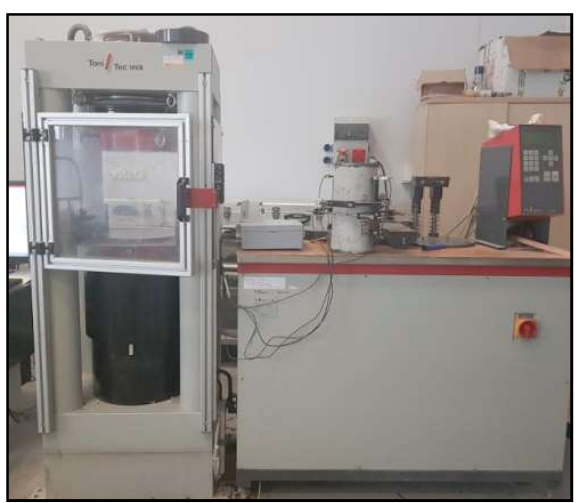

(a)

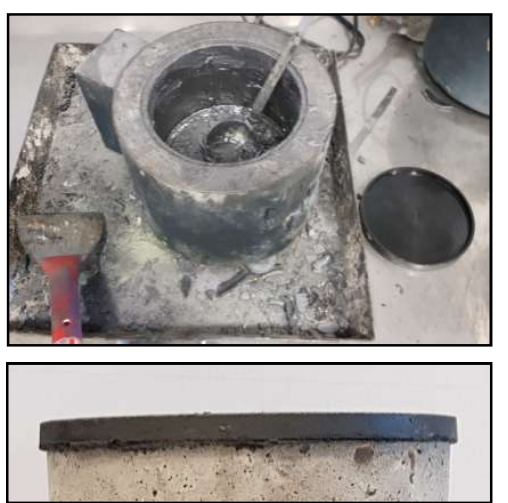

(b)

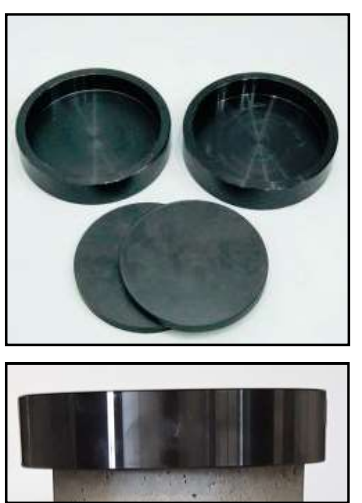

(c)

Şekil 3. a) Deneyler kullanılan hidrolik basınç presi, b) Kükürt+grafit karışımı başlıklama, c) Neopren başlıklama 

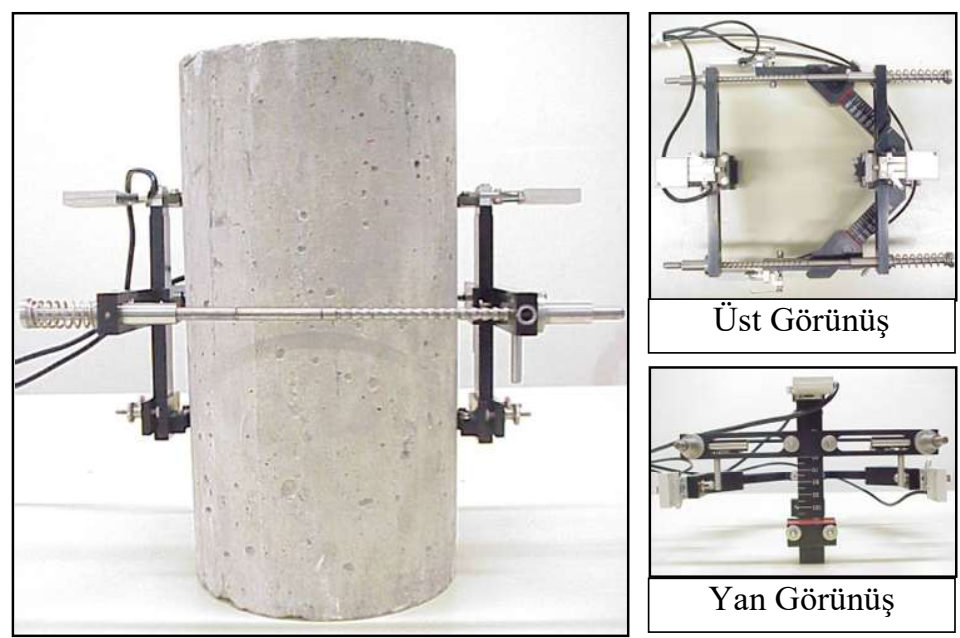

Şekil 4. Numuneye konumlandırılmış deformasyon ölçme çerçevesi

Kontrol numunelerinden elde edilen basınç dayanımı değerleri dikkate alınarak silindir numuneler basınç dayanımlarının \%40’ı oranında gerilmeye maruz kalacak şekilde yüklenmiştir [5]. E-modülü değerlerinin hesabında yükleme prosedürünün kararlı hale geldiği son çıkış kısmından elde edilen $\sigma-\varepsilon$ değerleri kullanılarak $\sigma-\varepsilon$ eğrileri çizdirilmiştir. Yükleme prosedürü ve örnek bir $\sigma-\varepsilon$ eğrisi Şekil 5'de sunulmuştur [5]. $\sigma$ - $\varepsilon$ eğrisi üzerinden elde edilen veriler Denklem 1‘de kullanılarak E-modülü değerleri hesaplanmıştır.

$$
E=\left(S_{2}-S_{1}\right) /\left(\varepsilon_{2}-0,000050\right)
$$

burada; E=Elastisite modülü, $\mathrm{S}_{1}: 5 \times 10^{-5}$ inci birim şekil değiştirmeye karş1lık gelen gerilme değerini, $\mathrm{S}_{2}$ maksimum basınç gerilmesinin \%40’ını $\left(0,40 \sigma_{\text {maks }}\right)$ ve $\varepsilon_{2}$ de bu gerilmeye karşılık gelen birim şekil değiştirme değerini ifade etmektedir.

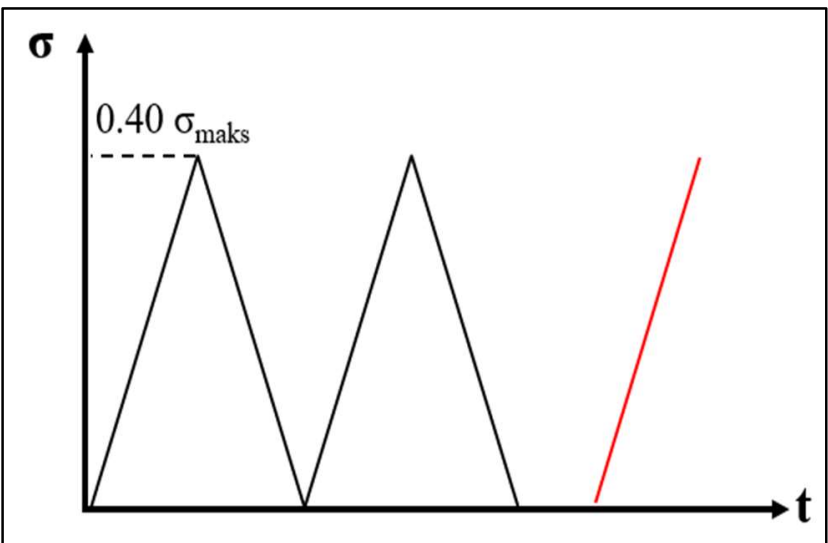

(a)

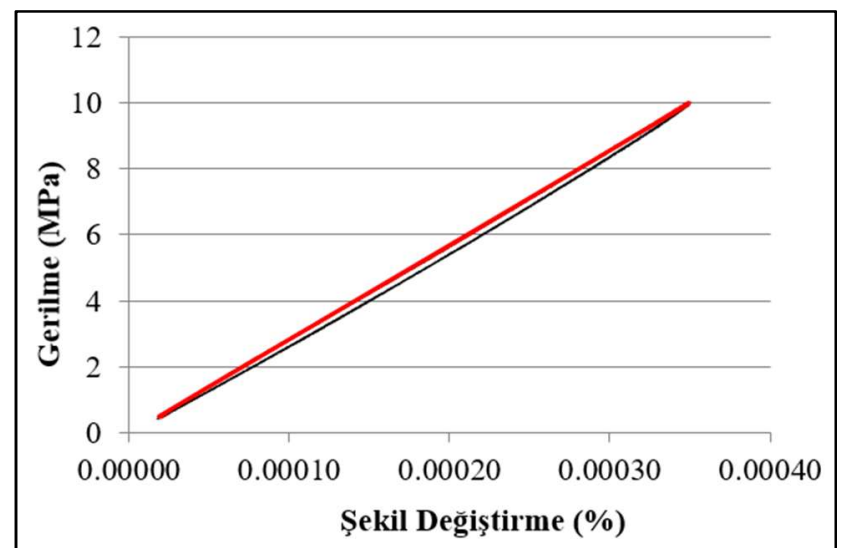

(b)

Şekil 5. a) ASTM C 469’a göre yükleme prosedürü, b) Örnek $\sigma-\varepsilon$ eğrisi.

\section{Bulgular ve Değerlendirme}

Numunelere farklı başlık kombinasyonlarında uygulanan basınç deneyi sonuçları Şekil 6'da verilmiştir. Genel olarak bakıldığında, başlıksız olarak yüklenen numunelerin en düşük basınç dayanımı değerlerini verdiği ve standart sapma açısından belirgin bir aralığın olduğu tespit edilmiştir. Kükürt başlıklama durumunda tek ve çift başlık uygulanmasının basınç dayanımı değerlerinde belirgin bir farklılığa neden olmadığı ancak çift başlıklama durumunda standart sapma açısından oldukça düşük değerlerin gözlendiği belirlenmiştir. Neopren başlik uygulanmış numunelerde ise aynı kombinasyonda kükürt başlık yapılarak deneye tabi tutulan numunelere kıyasla daha yüksek basınç dayanımı 
değerleri verdiği görülmektedir. Bu durumun, neopren başlıklama prosedüründe kullanılan kauçuğun kayma gerilmelerini absorbe ederek bu bölgelerde daha büyük gerilme yığılmaları oluşturmasından kaynaklanabileceği düşünülmektedir.

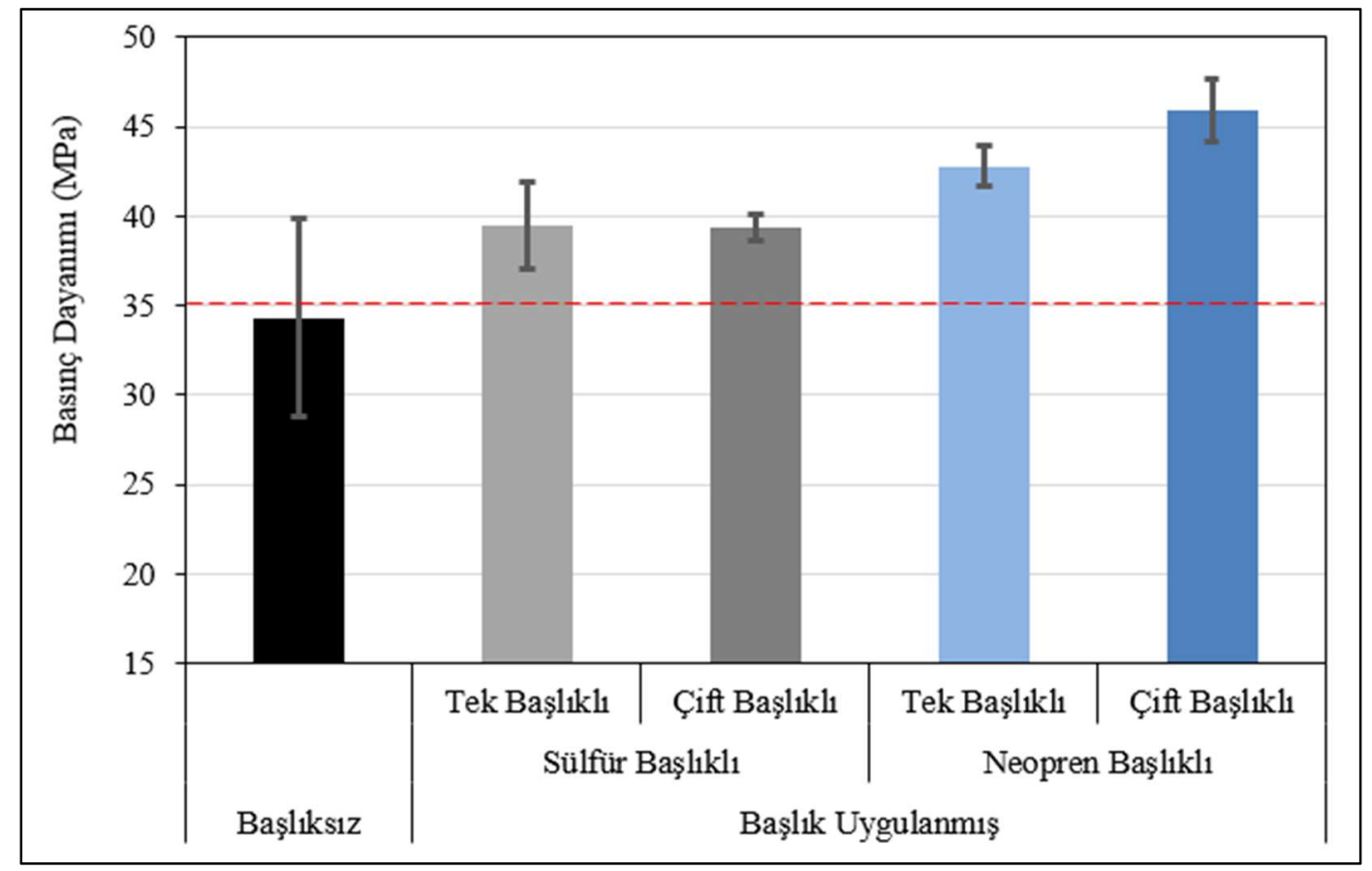

Şekil 6. Numunelere farklı başlık kombinasyonlarında uygulanan basınç deneyi sonuçları (*kırmızı kesikli çizgi hedeflenen basınç dayanımını belirtmektedir.)

Numuneler üzerinde farklı başlık kombinasyonlarında gerçekleştirilen E-modülü deney sonuçları Şekil 7'de sunulmuştur. Başlıksız durumda yapılan yüklemelerde, numune üzerinde yüklemenin erken safhalarında çatlamalar meydana gelmiş ve deney cihazlarında oluşabilecek hasar riskini engellemek amacıyla deney durdurularak veri alınamamıştır. Bu durum, basınç dayanımlarına bakılarak tahmin edilen elastik yük sınırının başlıksız yükleme altında numune yüzeylerindeki düzensiz yük dağılımına bağlı olarak yanıltıcı sonuçlar verebileceğinin bir kanıtı olarak gösterilebilir (Şekil 8a). Kükürt başlıklı numunelerin E-modülü değerlerini incelendiğinde, tek başlıklı yükleme durumda elde edilen E-modülü değerinin (24.1 GPa) çift başlıklı duruma kıyasla (26.4 GPa) daha düşük olduğu görülmüştür. Tek başlıklı durumda etkili yük aktarımının tüm yüzeye homojen olarak dağıtılamaması gerilme değerlerini düşürmüş, bu durum da $\sigma-\varepsilon$ eğrisine ait eğim değerlerinin dolayısıyla da hesaplanan E-modülü değerlerinin daha düşük çıkmasına neden olmuştur. Benzer bir durum neopren başlıklama durumda da tespit edilmiştir (tek başlıklama için $22.9 \mathrm{GPa}$; çift başlıklama için $25.5 \mathrm{GPa}$ ). Ayrıca, kükürt başlıklama durumunda elde edilen E-modülü değerlerinin neopren başlıklama durumuna kıyasla hem tek başlıklı hem de çift başlıklı durumlarda bir miktar daha fazla olduğu belirlenmiştir. Neopren ile yapılan deneylerde, yükleme sırasında neopren başlık ile numune temas yüzeylerinde çatlamalar meydana geldiği görülmüştür (Şekil 8b). Neopren başlıklarda oluşan gerilme yığılmalarına bağlı olarak neopren ile numune temas yüzeylerinde oluşan bu çatlamaların numune içerisinde de daha erken kılcal çatlak oluşturduğu ve bu nedenle E-modülü değerlerinin kükürt başlıklara kıyasla bir miktar azaldığı düşünülmektedir.

Çeşitli standartlardan [14-16] ve yayınlardan [17] elde edilen ampirik formüllerle hesaplanan E-modülü değerleri ile deneysel E-modülü değerleri kıyaslandığında (Şekil 7), ampirik formüllerle elde edilen E-modülü değerlerinin deneysel değerlere kıyasla genel olarak yüksek olduğu belirlenmiştir. En yakın sonuçların Amerika Beton Enstitüsü (ACI) [14] tarafından sunulan formül ile; en büyük farkın ise ülkemizde kullanılan Türk Standartlarının yayınlamış olduğu formülden [16] elde edilen değer ile olduğu tespit edilmiştir. 
Nevşehir Bilim ve Teknoloji Dergisi (2019), 9 (IMSTEC Özel Sayı),47-55

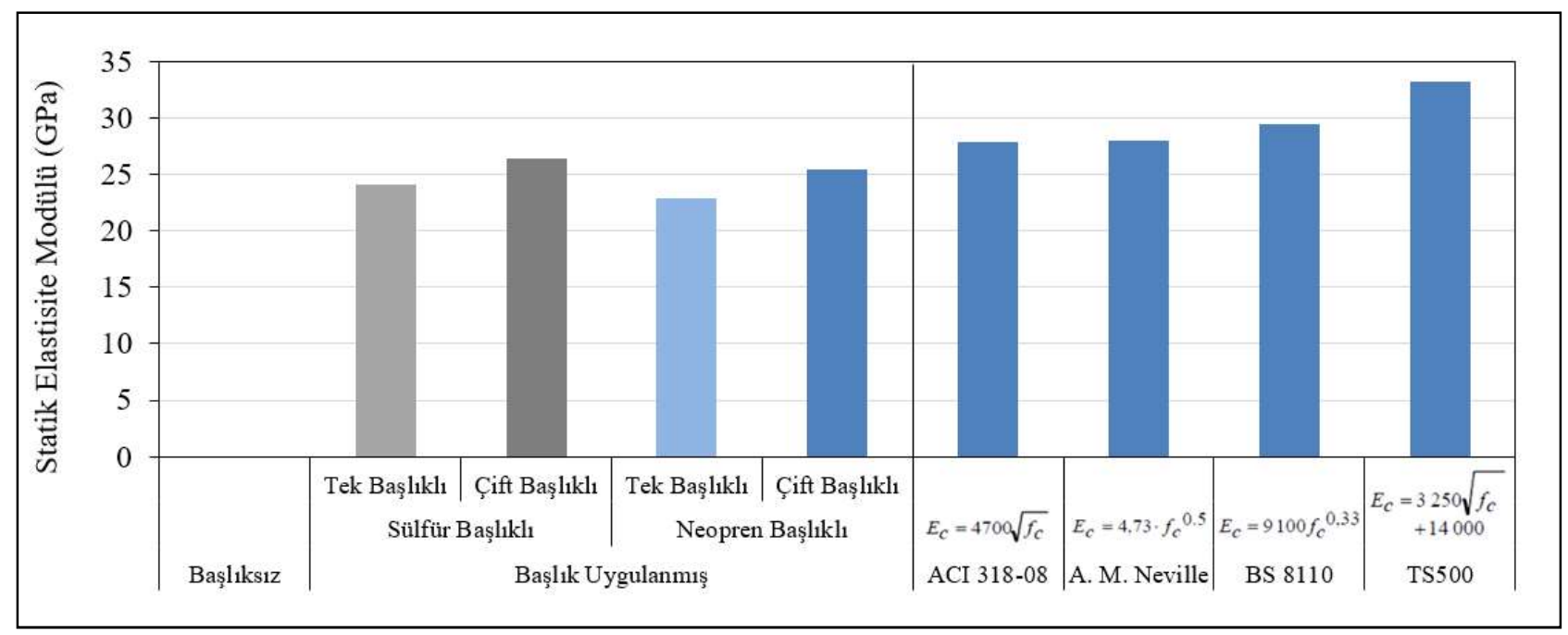

Şekil 7. Deneysel ve ampirik olarak hesaplanan E-modülü değerlerinin kıyaslanması

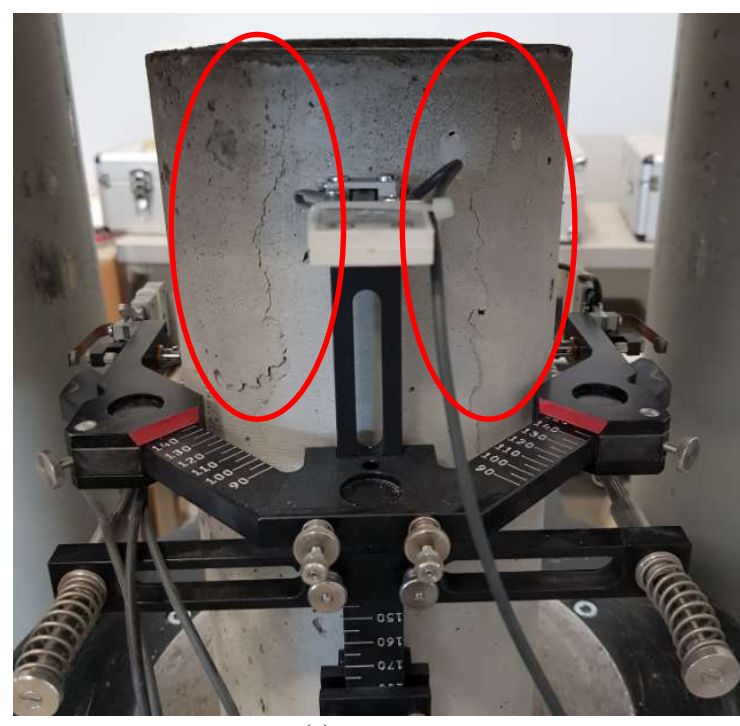

(a)

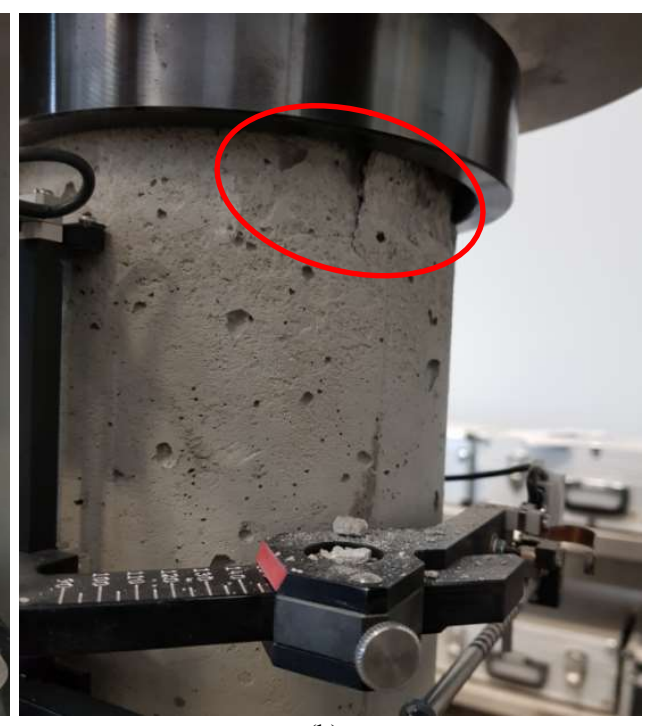

(b)

Şekil 8. a) Başlıksız yükleme durumunda oluşan çatlamalar, b) Neopren başlıklı yükleme durumunda oluşan çatlamalar

\section{Sonuç}

Çalışma kapsamında iki farklı malzeme (kükürt ve neopren) kullanılarak farklı kombinasyonlarda oluşturulan başlıklama durumlarının (başlıksız, tek başlıklı ve çift başlıklı) beton basınç dayanımı ve E-modülü parametrelerine etkisi incelenmiştir. Elde edilen bulgular değerlendirildiğinde aşağıdaki sonuçlar elde edilmiştir;

- Başlık yapılmadan yapılan basınç deneylerinden elde edilen sonuçların, beton tasarımından beklenen basınç dayanımını sağlayamadığı ve standart sapma değerleri de göz önüne alındığında kararlı bir davranış

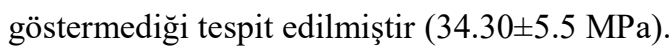

- Kükürt başlık uygulanarak elde edilen basınç değerlerinin beklenene daha yakın sonuçlar verdiği görülmüştür. Kükürt başlığın çift taraflı uygulanması durumunda alınan basınç dayanım değerlerinin de daha kararlı olduğu görülmüştür.

- Neopren başlık kullanılması durumunda elde edilen basınç dayanımlarının kükürt başlıklama durumuna kıyasla daha yüksek olduğu belirlenmiştir. Başlıksız, tek başlıklı ve çift başlıklı durumlar için kükürt 
Nevşehir Bilim ve Teknoloji Dergisi (2019), 9 (IMSTEC Özel Sayı),47-55

başlıklamaya kıyasla sırasıyla $\% 15, \% 8$ ve $\% 17$ oranında daha yüksek basınç dayanımları elde edilmiştir. Söz konusu durumun, neopren başlıklarda meydana gelen gerilme yığılmalarından kaynaklandı̆̆ düşünülmektedir.

- Başlıksız olarak yapılmaya çalışılan E-modülü deneylerinde, yükleme sırasında numunenin tahmin edilen elastik bölge içerisinde çatlaklar oluşturduğu görülmüş, söz konusu yükleme durumunun hem basınç hem de E-modülü deneyleri açısından elverişsiz olduğu belirlenmiştir.

- Hem kükürt hem de neopren başlıklama durumlarında, etkili ve homojen bir yük aktarımı sağlayan çift başlıklama durumunun tek başlıklamaya kıyasla daha yüksek E-modülü değerleri verdiği görülmüştür. Çift kükürt başlıklama ile yapılan E-modülü deneylerinde en yüksek E-modülü değerleri elde edilmiştir. Bu değerler, literatürde verilen ampirik formüller kullanılarak elde edilen E-modülü değerleri ile kıyaslandığında en anlamlı sonucu vermektedir.

- Neopren başlıklama durumlarında yapılan E-modülü deneylerinde de başlık-numune birleşim bölgesinde çatlamaların oluştuğu ve bu durumun kükürt başlıklamaya kıyasla E-modülü değerlerinde tek başlıklı durumda \%5.1, çift başlıklı durumda ise \%3.7 oranında azalmaya neden olduğu tespit edilmiştir.

Genel bir değerlendirme yapılacak olursa, günümüzde hem basınç hem de E-modülü deneylerinin gerçekleştirilmesi sırasında çift taraflı kükürt başlıklamanın gerekliliği bir kez daha ortaya konulmuştur. Bilinçli ve bilgili teknik eleman eksikliğinde alınacak basınç dayanımı ve E-modülü değerlerinin gerçek duruma kıyasla farklılıklar oluşturabileceği görülmüştür. Neopren başlıklamanın ise kükürt başlıklamaya kıyasla bir alternatif olarak farklı beton sınıflarında kullanılabilirliği üzerine daha çok araştırma yapılması gerektiği düşünülmektedir.

\section{Kaynaklar}

[1] Shetty, M. S., “Concrete Technology”, S. Chand \& Company Ltd, 420-453, 2005

[2] TS 500, "Betonarme yapıların tasarım ve yapım kuralları", Türk Standartları Enstitüsü, Ankara, 2000

[3] TS EN 12390-3, "Beton - Sertleşmiş beton deneyleri - Bölüm 3: Deney numunelerinde basınç dayanımının tayini”, Türk Standartları Enstitüsü, Ankara, 2010

[4] Topçu, İ. B., Uğurlu, A., "Betonda elastisite kuramı ve baraj betonları için statik e-modülünün kompozit modellerle tahmini”, Teknik Dergi, 18(86), 4055-4067, 2007

[5] ASTM C469 / C469M-14, "Standard Test Method for Static Modulus of Elasticity and Poisson's Ratio of Concrete in Compression", ASTM International, West Conshohocken, PA, 2014

[6] ASTM C1231 / C1231M-15, "Standard Practice for Use of Unbonded Caps in Determination of Compressive Strength of Hardened Cylindrical Concrete Specimens", ASTM International, West Conshohocken, PA, 2015

[7] Carrasquillo, P. M., Carrasquillo, R. L., "Effect of using unbonded capping systems on the compressive strength of concrete cylinders", Materials Journal, 85(3), 141-147, 1987

[8] Aydın, F., Akça, K. R., Sarıbıyık, M., İpek, M., "Silindir Beton ve Karot Numunelerde Yeni Bir Başlıklama Malzemesinin Kullanılması", In 5th International Symposium on Innovative Technologies in Engineering and Science, 29-30 September, Baku-Azerbaijan, 2017

[9] ASTM C617 / C617M-15, "Standard Practice for Capping Cylindrical Concrete Specimens", ASTM International, West Conshohocken, PA, 2015 
Nevşehir Bilim ve Teknoloji Dergisi (2019), 9 (IMSTEC Özel Sayı),47-55

[10] Ballard, J. R., "Analysis of Unbonded Capping Materials Used in Determining the Compressive Strength of Concrete Masonry Prisms”, Master's Degree Thesis, Brigham Young University, 2012

[11] Richardson, D., "Effects of testing variables on the comprison of neoprene pad and sulphur mortar -capped concrete test cylinders", ACI Materials Journal, 87(5), 489-495, 1990

[12] Sancak, E., Gökdemir, A., “Ankara'daki Hazır Beton Tesisleri Teknik Personelinin Eğitim Düzeyleri”, Yapı Teknolojileri Elektronik Dergisi, 4(1), 47-57, 2008

[13] Öztoprak, B., Sözen, Ş., Çavuş, M., "Bolu Bölgesindeki Hazır Beton Tesislerinin Durumu ve Beton Kalitesini Etkileyen Faktörler”, Gaziosmanpaşa Bilimsel Araştırma Dergisi, 7(3), 1-11, 2018

[14] ACI 318-08, "Building code requirements for structural concrete and commentary", ACI Committee and International Organization for Standardization, American Concrete Institute, 2008

[15] BS EN 1992-1 / A1, "Eurocode 2: Design of concrete structures. General rules and rules for buildings", British Standard Institution, 2004

[16] TS 500/T3, “Betonarme yapıların tasarım ve yapım kuralları”, Türk Standartları Enstitüsü, Ankara, 2014 